\section{Food shopping and food hygiene related knowledge and practices during the COVID-19 pandemic: The case of a developing country}

\author{
Hani Dimassi, ${ }^{1}$ Rita Haddad, ${ }^{2}$ \\ Rana Awada, ${ }^{3,4}$ Lama Mattar, ${ }^{2}$ \\ Hussein F. Hassan, ${ }^{2}$
}

${ }^{1}$ School of Pharmacy, Lebanese American University, Byblos; ${ }^{2}$ Department of Natural Sciences, Nutrition Program, School of Arts and Sciences, Lebanese American University, Beirut; ${ }^{3}$ Rammal Hassan Research Laboratory, Physio-toxicity Research Group, Faculty of Sciences, Lebanese University, Nabatieh; ${ }^{4}$ Department of Veterinary Sciences, Faculty of Agronomy, Lebanese University, Dekwaneh, Lebanon

\begin{abstract}
The aim of this study was to assess the level of food hygiene and food shopping knowledge and practices among residents of Lebanon during the COVID-19 pandemic, and to identify their socio-demographic determinants. A cross-sectional study was conducted through an online questionnaire composed of 13 questions about demographics, and 25 questions related to knowledge and practices in terms of hand maintenance, mask placing, and food shopping. A total of 1337 participants filled the survey. On average, participants scored $73 \pm 15$ and $67 \pm 17 \%$ on food hygiene and knowledge and practices, respectively. In terms of best practices by section, they scored $77 \pm 22,51 \pm 42$, and $65 \pm 23 \%$ on hand maintenance, mask placing and shopping, respectively. Hand maintenance best practices score was significantly $(p<0.05)$ affected by gender; mask placing best practices score was significantly affected by age and major of study; shopping best practices score was significantly affected by gender; overall best practices score was significantly affected by gender and major of study; food hygiene knowledge score was significantly affected by gender, age, marital status, educational level, and major of study. Food hygiene practices and knowledge scores were significantly $(\mathrm{p}<0.001)$ related with a weak correlation coefficient $(\mathrm{R}=0.114)$. No study has determined the food hygiene and shopping knowledge and practices during the COVID-19 pandemic in a developing country before.
\end{abstract}

\section{Introduction}

The world is facing an unprecedented threat from the coronavirus disease (COVID-19) pandemic caused by the SARS-CoV-2 (coronavirus). The primary method of transmitting COVID-19 is droplet spread from being close to an infected person (who may have no symptoms). This particular coronavirus causes respiratory illness and is spread from person-toperson, unlike foodborne gastrointestinal or GI viruses, such as norovirus and hepatitis A that often make people ill through contaminated food (WHO, 2020). Scientists and health authorities around the world are closely monitoring the spread of COVID19, and social distancing remains the most important way to mitigate the risk of contagion (FDA, 2020; Health Canada, 2020). While there is no published evidence of contracting COVID-19 from touching food or food packaging that came in contact with the virus due to coughing or sneezing from an infected person, the virus can survive on surfaces and objects for up to about 3 days on hard surfaces like metal or plastic, and about 1 day on soft surfaces like cardboard (van Doremalen et al., 2020).

At home, Health Canada recommends to use common cleaning and disinfection methods, to wash hands with soap and warm water for at least 20 seconds before and after handling food and food packaging, and to avoid washing fresh produce with soap, chlorine or other chemicals whenever safe running water is not available (vinegar is not effective in this regard). In addition, food must be cooked to recommended safe internal temperatures as the virus is killed by normal cooking temperatures. Crosscontamination of raw and ready-to-eat or cooked foods must be avoided, and any surfaces that will come in contact with food must be disinfected (Health Canada, 2020).

In terms of shopping behavior, it is recommended that a shopping list be prepared in advance, to buy 1 to 2 weeks-worth of groceries at a time, to use hand sanitizers when entering and exiting the store, and one's own clean reusable grocery bags. Furthermore, a distance of approximately 2 meters from other people while shopping must be maintained, trips to the store at peak hours must be minimized to avoid crowds, and touching items that the customer is not going to take must be avoided. Also, touching eyes, nose and mouth must be avoided, a face covering or mask must be worn while in the store, and hands must be washed when getting back home. In addition, contactless payment (online, tap and go, mobile) and contactless delivery by having food dropped off at the doorstep are rec-
Correspondence: Hussein F. Hassan, P.O. Box 13-505 Chouran Beirut, Lebanon.

Tel.: 11022801 - 009611786456.

E-mail: hussein.hassan@lau.edu.lb

Key words: Food, Hygiene, Shopping, Lebanon, COVID-19.

Conflict of interest: The authors declare no potential conflict of interest.

Funding: None.

Ethics approval: Approval of the Institutional Review Board at the Lebanese American University was obtained prior to approaching the participants.

Availability of data and materials: Not applicable

Received for publication: 5 October 2020

Revision received: 15 May 2021

Accepted for publication: 20 May 2021.

This work is licensed under a Creative Commons Attribution-NonCommercial 4.0 International License (CC BY-NC 4.0).

C) Copyright: the Author(s), 2021

Licensee PAGEPress, Italy

Italian Journal of Food Safety 2021; 10:9384

doi:10.4081/ijfs.2021.9384

ommended whenever possible (FDA, 2020; Health Canada, 2020).

Understanding the knowledge and practices related to food hygiene and food shopping can be used for designing effective interventions to help in mitigating the COVID-19 health consequences. Identifying the demographics of the groups with the lowest knowledge is the point from which an educational program can be tailored. Many studies in the literature have reported the demographic characteristics of social classification, income, gender, education level, age, and residential location as contributing factors to food handling knowledge and practices (Unusan, 2007; Sanlier, 2009; Gong et al., 2011; Hassan \& Dimassi, 2014; Ovca, Jevsnik, \& Raspor, 2014; Migliorati et al., 2015; Hassan et al., 2018). These studies show mixed results due to variations in study designs, study populations, and survey questions. In Lebanon, we investigated the food hygiene knowledge and practices among university students and food handlers in households (Hassan and Dimassi, 2014; Hassan et al., 2018). The objective of this study was to assess the self-reported food hygiene and shopping knowledge and practices in Lebanon during COVID-19, in order to measure the post-pandemic changes in this 
regard, and to detect the demographic characteristics of "high-risk" groups with the poorest knowledge. This will provide practical guidance for tailoring targeted educational programs.

\section{Materials and methods}

\section{Study population}

In compliance with social distancing measures, and after obtaining consent from the university's Institutional Review Board, established in accordance with the US Code of Federal Regulation (45CFR 46.107, 21CFR 56.107), and Good Clinical Practice ICH (Section 3), and using a cross-sectional observational design, data was collected via a short 15-minute Google form-based questionnaire from a convenient sample that filled it. The questionnaire was broadcasted on different social media platforms of the researchers, our university and influential acquaintances. Also, nutrition students at our university broadcasted the link to the questionnaires via WhatsApp to ensure recruitment of participants from different regions, age groups, genders, and socioeconomic statuses. The completion of the questionnaire was voluntary and anonymous, and no extra credit was given. Incomplete questionnaires were excluded automatically. One thousand three hundred and thirtyseven questionnaires were completed.

\section{Questionnaire}

A questionnaire, composed of 3 sections and 38 questions. Reliable and valid food hygiene instruments (Osaili et al., 2011; Gong et al., 2016; Byrd-Bredbenner et al., 2007; Hassan \& Dimassi, 2014; Hassan \& Dimassi, 2017) were used as starting point. General food hygiene questions (related to personal hygiene for example) were kept, while COVID-19 specific questions were added (Tables 1 and 2) based on the recommendations of the World Health Organization, Canada (Health Canada), USA (CDC and FDA) as the local recommendations pertaining to CVODI-19 were developed based on these aforementioned sources. The questionnaire got translated to Arabic by a sworn translator and back translated to English to validate the translation. Both versions were piloted to assess clarity and the average time needed for its completion. The first section of the questionnaire (13 questions) was concerned about general demographic characteristics of the participants (gender, age, area of residence, marital status, educational level, educational background, and number of people living in the house), in addition to questions related to who cooks at home, frequency of cooking before and during the crisis, abiding to social distancing and stay at home. The second section (15 questions) was about the food hygiene and shopping practices (Table 1); while the third section (10 questions) was about the food hygiene knowledge (Table 2).

\section{Statistical analysis}

SPSS v23 Statistical computer software was used to perform all statistical analyses. The demographic characteristics represented the independent variables. Overall food hygiene knowledge (10 questions), overall food hygiene and shopping practices score (13 questions), hand maintenance best practices score (5 questions), mask placing best practices score (2 questions), shopping best practice score (6 questions) represented the dependent variables (Tables 1 and 2). Each question was given one point if answered correctly and zero point if answered incorrectly. Frequencies (counts and percentages) were calculated for each answer choice. Mean score and the standard deviation were calculated for all sections. The scores were converted to 100 . Student $t$ test for independent groups was used to compare the mean sum of correct responses of every section by gender, age, residential area, major of study, marital status, educational level, major of study, number of people living in the house, and abiding to social distancing/stay at home. Normal distribution assumptions of scores were tested using the Kolmogorov-Smirnov test, Shapiro Wilk test, mean vs. median, Q-Q plots, and standardized Skewness and kurtosis. Differences in proportions were tested using the Pearson's chi-square for independent groups and the Mc Nemar Chi-square for paired groups. Significance level of 0.05 was used.

Table 1. Practice questions and their corresponding best practice answers used to calculate the score for each section.

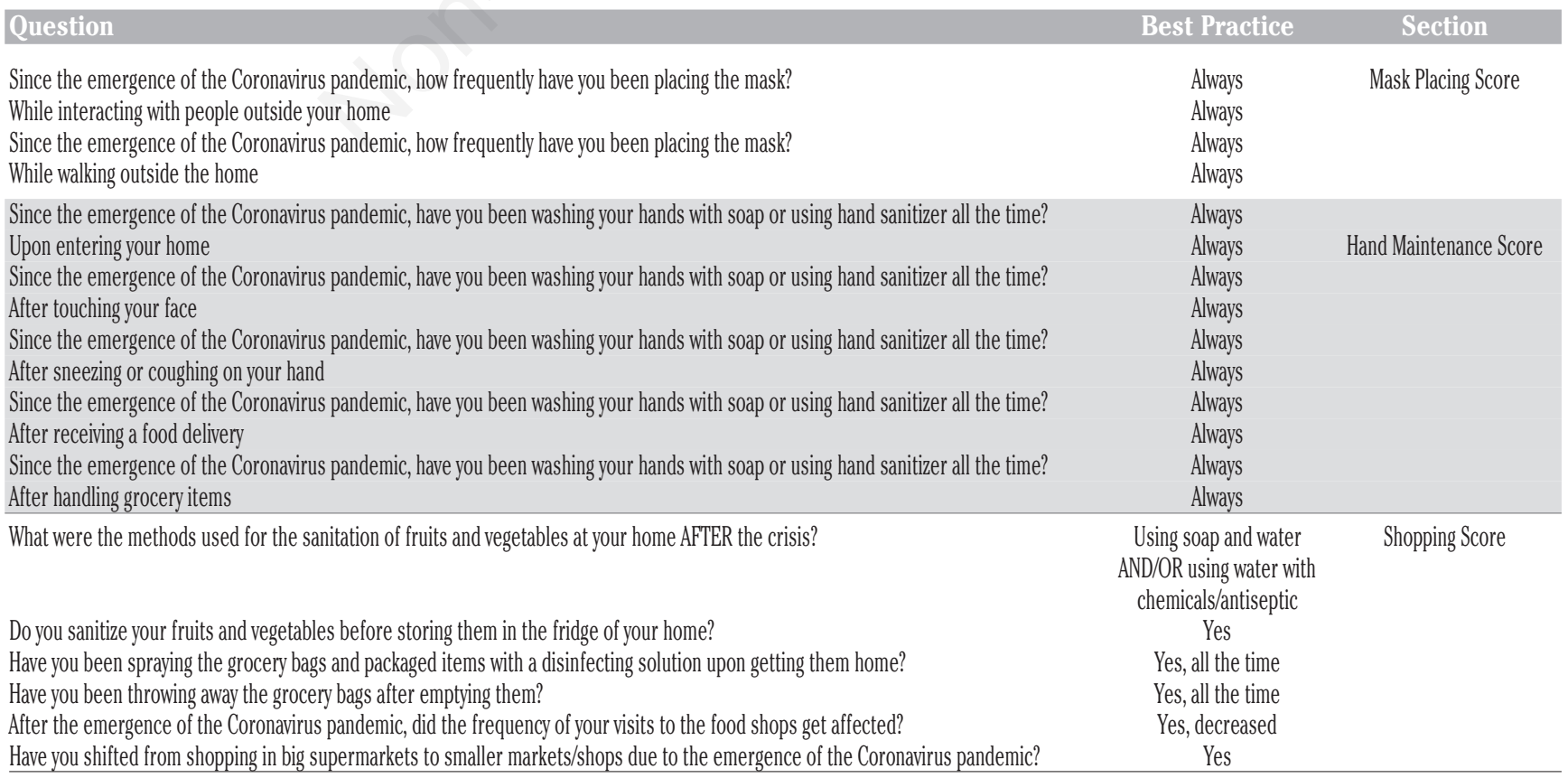


al., 2018). Our study presents insights into the food hygiene and shopping practices, and food hygiene knowledge among residents of a developing country, Lebanon, in time of pandemics, like COVID-19. In terms of food hygiene knowledge, our study reported a score of $73.6 \%$, which is higher to the score $(71.3 \%)$ reported by Hassan et al. (2018) among domestic food handlers in Lebanon, and that $(53.6 \%)$ reported by Hassan and Dimassi (2014) among Lebanese university students, knowing the aforementioned two studies did not use exactly the same questions as in the present study. On the other hand, in terms of food hygiene and shopping practices, our study reported a score of $68.0 \%$, which is higher than the score $(59.7 \%)$ reported by Hassan et al. (2018) among domestic food handlers in Lebanon, and that (44.7\%) reported by Hassan and Dimassi (2014) among Lebanese university students. This can be attributed to the massive COVID-19 related awareness campaigns done on different media outlets. Only $37 \%$ of participants reported putting the mask on while walking outside home (Supplementary Tables), and $37.2 \%$ reported washing their hands or applying hand sanitizers after touching their face (Supplementary Tables), which is alarming. These two malpractices must be highlighted in awareness campaigns. Supplementary Tables. Mean score of the hand maintenance best practices was $77 \%$ $(\mathrm{SD}=22)$, and women scored significantly better $(p<0.05)$, while the marital status was borderline significant $(p=0.07)$. In terms of mask placing best practices, mean score was $51 \%(\mathrm{SD}=42)$, and older participants ( $\geq 35$ years) who had a health related major (Nutrition, Chemistry, Biology, Nursing and Pharmacy) scored significantly better $(p<0.05)$. On the other hand, mean score of the shopping best practices was $65 \%$ (SD = 23 ), and females scored significantly better $(p<0.05)$, while the major of study was borderline significant $(\mathrm{p}=0.07)$. In terms of overall best practices score, the mean value was $68 \%(S D=18)$, and women participants who had a health related major scored significantly better $(\mathrm{p}<0.05)$. With regard to the food hygiene knowledge score, mean value was $74 \%(\mathrm{SD}=15)$, and the significant difference was found among old ( $\geq 35$ years), married, female, who had a health related, university degree, scored significantly better $(\mathrm{p}<0.05)$ (Table 4$)$.

Literature reported the fact that women, older participants, married, and those having health related major scored higher when it comes to food hygiene knowledge and practices. This is attributed to the fact that, in developing countries, including Lebanon, women are traditionally in charge of food shopping and kitchen hygiene and cleaning (Hassan et al., 2018). In addition, participants with a health education background took modules and courses relevant to food hygiene, hygiene and microbiology in the curricula of their majors. Also, married participants had offspring in general, which makes them more responsible towards their offspring and food hygiene aware. Furthermore, older participants got more likely exposed to health messages throughout years, explaining why they scored higher in all sections (Unklesbay et al., 1998; Garayoa et al., 2005; Byrd-Bredbenner et al., 2007; Sharif \& AlMalki, 2010; Osaili et al., 2011; Lazou et al., 2012; Ovca et al., 2014; Hassan and Dimassi, 2014; Hassan et

Table 2. Demographic characteristics of the sample $(n=1337)$.

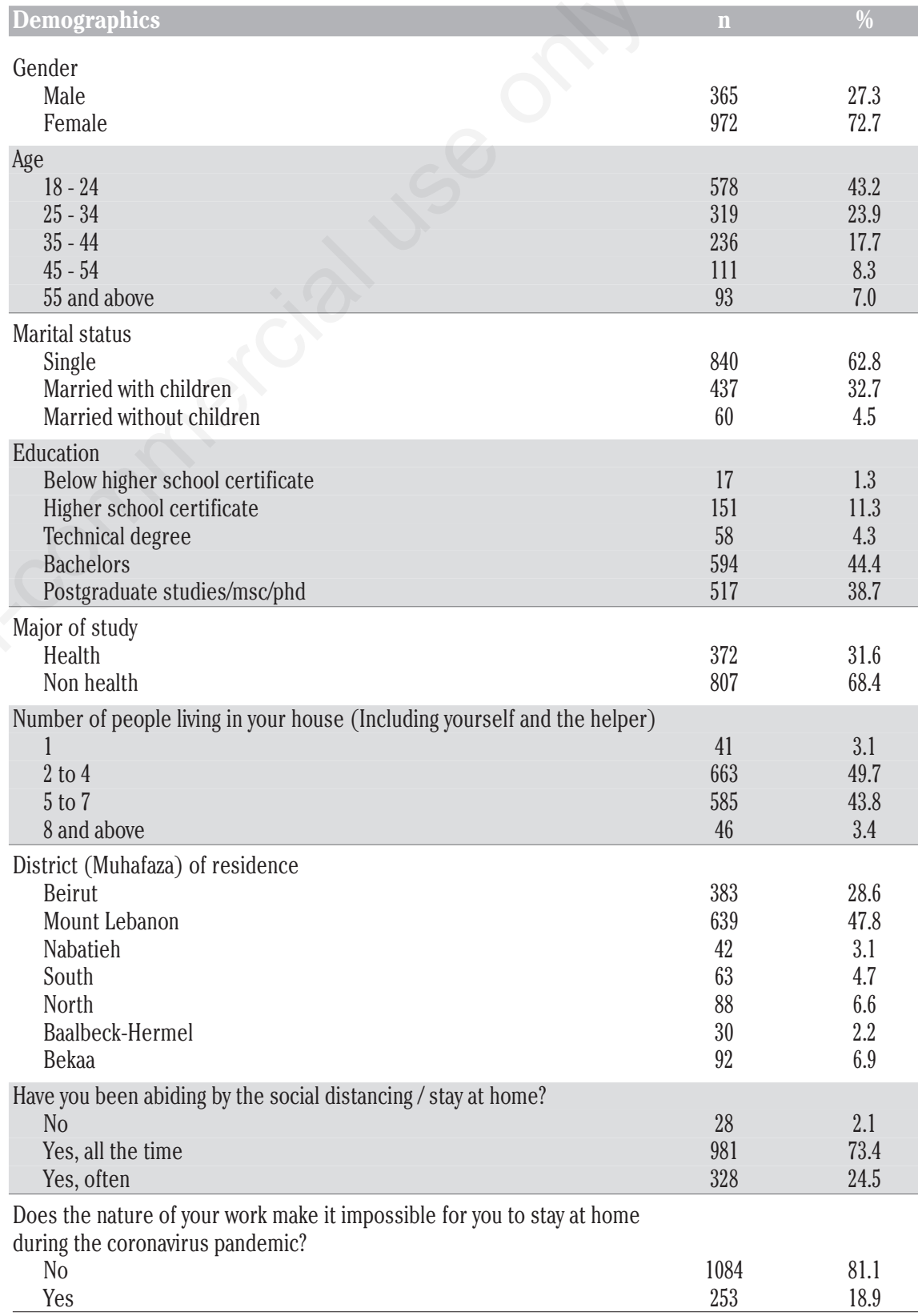


Applying different methods to sanitize produce increased significantly $(p<0.05)$ after the pandemic emerged (Supplementary Tables). Sanitizing produce by immersing in a vinegar or brine solution was the most common practice before and after COVID-19, followed by the use of soap and water, the use of chemicals, and the use of water only. While authorities in many countries recommend applying water only (CDC, 2020; Health Canada, 2020), this cannot be applicable to developing countries, like Lebanon, due to the contamination of water supply. Instead, using a chemical can be the best alternative as long as the proper dilution is used as per the manufacturer's instructions. Using the soap is a good option, but improper rinsing may result in toxic residues. Vinegar and salt were found to be ineffective against SARS-
CoV-2 (US EPA, 2020). Awareness campaigns must address this point.

In terms of produce sanitizing prior to storage, and disinfecting grocery bags and packaged foods, there was a high positive rate ( 82.2 and $77.6 \%$, respectively) reported by respondents (Supplementary Tables), which matches the recommendations. On the other hand, the frequency of using home delivery service of food shops and restau-

Table 3. Answers to the food hygiene and knowledge questions.

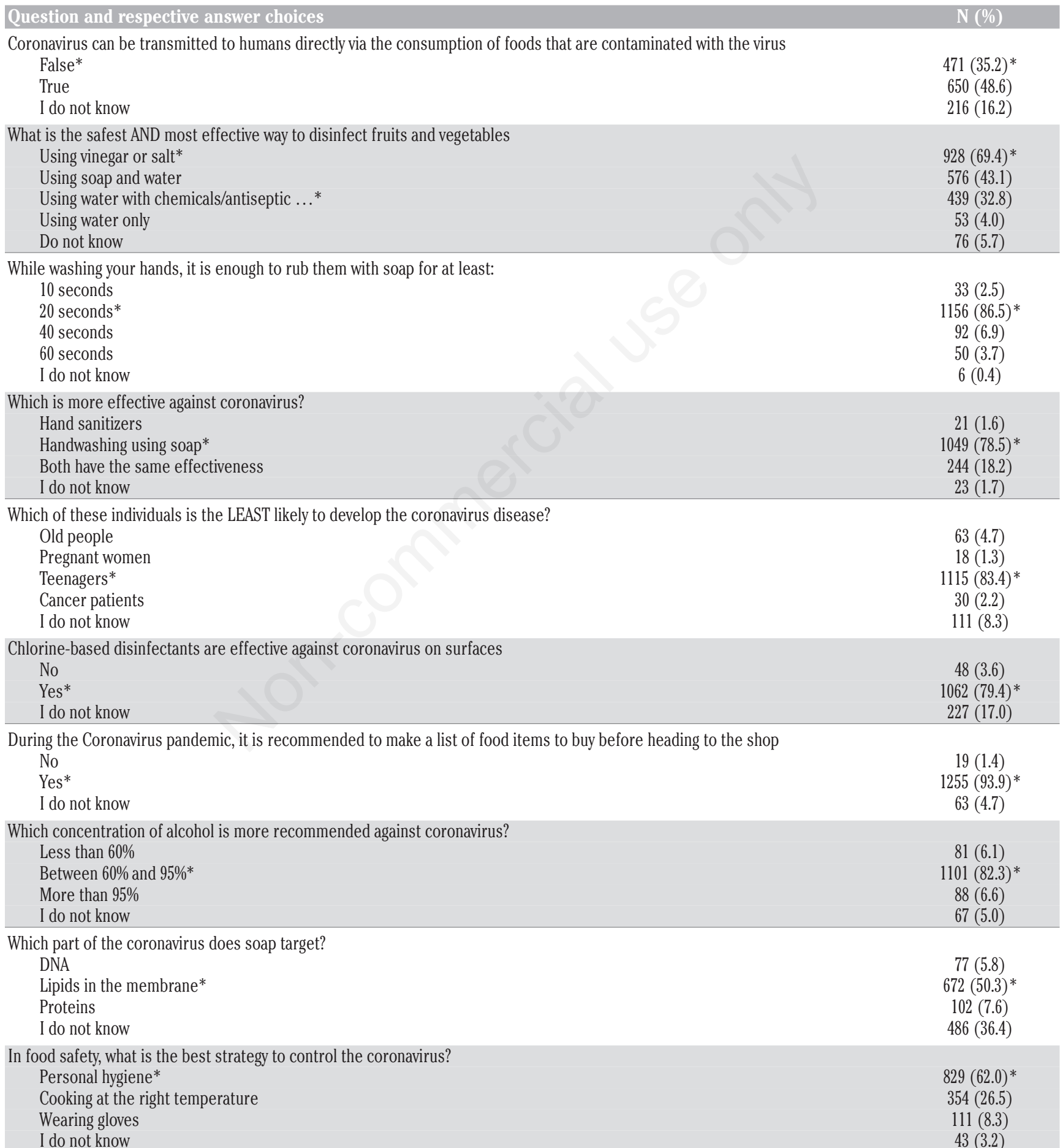

${ }^{*}$ Correct answer. 
rants decreased significantly $(\mathrm{p}<0.05)$ after the pandemic (Supplementary Tables), which can be attributed to the shift of consumers to cook at home while in lockdown.

As for the frequency of visits to food shops, $916(68.5 \%)$ of the respondents reported that it decreased, and this was significant $(\mathrm{p}<0.05)$ (Supplementary Tables). This goes in line with the recommendations of international health authorities in order to reduce the contact between people (CDC, 2020; FDA, 2020; Health Canada, 2020). Regarding the shift from shopping in big food shops to smaller ones, only 406 (30.4\%) among those who do not usually shop at small shops reported that they did (Supplementary Tables), which is against the recommendations to visit smaller shops as they tend to be less crowded (CDC, 2020; Health Canada, 2020). The latter point must be tackled in the ongoing awareness campaigns.

In terms of changes in the consumption of meat and produce, there was no significant $(p<0.05)$ change in frozen meat and canned fruits and vegetables. On the other hand, significant $(\mathrm{p}<0.05)$ reduction was reported in fresh meat, and significant $(p<0.05)$ increase was reported in frozen and fresh fruits and vegetables (Supplementary Tables). This can be attributed to the fact that consumers shifted towards consuming fruits and vegetables due to increased awareness about healthy eating and the fact that produce are rich in nutrients that can help in boosting the immune system. Since fresh meat is a highrisk product, increased awareness about the importance of avoiding foodborne illnesses as this compromise the immunity can explain the decrease in its consumption.

The bivariate analysis showed that food hygiene and knowledge practices, and food hygiene knowledge scores were significantly $(\mathrm{p}<0.001)$ related; however, the correlation was weak $(\mathrm{R}=0.114)$. Such findings highlight the importance of increasing or reinventing the awareness campaigns to improve their effectiveness in improving the knowledge and practices during the
COVID-19 pandemic

Although its limitations related to the design as sampling was not a true random sample, in addition to the fact that data consisted of self-reports, introducing the possibility of a mono-method bias, and data were collected using online questionnaires, while many people do not have access to internet or do not have smart phones to fill them, our study gave considerable insights to the status of food hygiene and food shopping knowledge and practices in Lebanon.

\section{Conclusions}

The notable low awareness about food hygiene, as indicated by low practices scores reported by Lebanese respondents, contributes, at the short term, to higher susceptibility to food poisoning and higher likelihood to get SARS-CoV-2 infected. Particular focus should be given to younger adults, single, men and those who do not

Table 4. Relations between demographic characteristics and practices/knowledge scores.

\begin{tabular}{|c|c|c|c|c|c|}
\hline Variable & $\begin{array}{l}\text { Hand maintenance } \\
\text { best practices score }(\%) \text {, } \\
\text { mean }( \pm \text { SD) }\end{array}$ & $\begin{array}{l}\text { Mask placing best } \\
\text { practices score }(\%) \text {, } \\
\text { mean }( \pm \text { SD) }\end{array}$ & $\begin{array}{l}\text { Shopping best practices } \\
\text { score }(\%), \\
\text { mean }( \pm \text { SD) }\end{array}$ & $\begin{array}{l}\text { Overall best practices } \\
\text { score }(\%), \\
\text { mean }( \pm \text { SD) }\end{array}$ & $\begin{array}{l}\text { Food hygiene } \\
\text { knowledge score }(\%) \text {, } \\
\text { mean ( } \pm \text { SD) }\end{array}$ \\
\hline Score & $77( \pm 22)$ & $51( \pm 42)$ & $65( \pm 23)$ & $68.0( \pm 18)$ & $73.6( \pm 15.0)$ \\
\hline $\begin{array}{l}\text { Gender } \\
\text { Male } \\
\text { Female } \\
p \text {-value }\end{array}$ & $\begin{array}{c}71( \pm 25) \\
79( \pm 20) \\
<0.01\end{array}$ & $\begin{array}{c}51( \pm 43) \\
51( \pm 42) \\
0.937\end{array}$ & $\begin{array}{c}63( \pm 24) \\
66( \pm 23) \\
0.023\end{array}$ & $\begin{array}{l}64.3( \pm 19.7) \\
68.7( \pm 16.9) \\
\quad<0.01\end{array}$ & $\begin{array}{c}71.2( \pm 15.4) \\
74.5( \pm 14.7) \\
\quad<0.01\end{array}$ \\
\hline $\begin{array}{l}\text { Age } \\
18 \text { - } 34 \text { years old } \\
\geq 35 \text { years old } \\
p \text {-value }\end{array}$ & $\begin{array}{c}76( \pm 23) \\
78( \pm 20) \\
0.132\end{array}$ & $\begin{array}{l}49( \pm 17) \\
55( \pm 16) \\
0.02\end{array}$ & $\begin{array}{c}65( \pm 23) \\
66( \pm 23) \\
0.718\end{array}$ & $\begin{array}{c}66.9( \pm 18.1) \\
68.7( \pm 17.2) \\
0.082\end{array}$ & $\begin{array}{c}72.9( \pm 15.3) \\
75.2( \pm 14.0) \\
0.006\end{array}$ \\
\hline $\begin{array}{l}\text { Marital status } \\
\text { Single } \\
\text { Married (with/without children) } \\
\text { p-value }\end{array}$ & $\begin{array}{c}76( \pm 23) \\
78( \pm 20) \\
0.065\end{array}$ & $\begin{array}{c}50( \pm 17) \\
53( \pm 16) \\
0.185\end{array}$ & $\begin{array}{c}65( \pm 23) \\
66( \pm 23) \\
0.699\end{array}$ & $\begin{array}{c}66.9( \pm 18.2) \\
68.5( \pm 17.3) \\
0.123\end{array}$ & $\begin{array}{c}72.7( \pm 15.2) \\
75.2( \pm 14.5) \\
0.003\end{array}$ \\
\hline $\begin{array}{l}\text { Educational level } \\
\text { Below Higher School Certificate/ } \\
\text { Higher School Certificate } \\
\text { Technical degree/ Bachelors/ } \\
\text { Postgraduate studies/MSc/PhD } \\
\text { p-value }\end{array}$ & $\begin{array}{c}77( \pm 21) \\
77( \pm 22) \\
0.714\end{array}$ & $\begin{array}{c}53( \pm 18) \\
51( \pm 17) \\
0.62\end{array}$ & $\begin{array}{c}63( \pm 24) \\
63( \pm 23) \\
0.261\end{array}$ & $\begin{array}{c}67.2( \pm 18.3) \\
67.5( \pm 17.8) \\
0.764\end{array}$ & $\begin{array}{l}67.6( \pm 16.6) \\
74.5( \pm 14.5) \\
<0.01\end{array}$ \\
\hline $\begin{array}{l}\text { Major of study } \\
\text { Health } \\
\text { Non Health } \\
p \text {-value }\end{array}$ & $\begin{array}{c}77( \pm 22) \\
77( \pm 22) \\
0.82\end{array}$ & $\begin{array}{c}46( \pm 17) \\
55( \pm 17) \\
0.001\end{array}$ & $\begin{array}{c}64( \pm 23) \\
66( \pm 23) \\
0.067\end{array}$ & $\begin{array}{c}66.2( \pm 17.2) \\
68.6( \pm 18.0) \\
0.029\end{array}$ & $\begin{array}{c}79.1( \pm 12.7) \\
71.1( \pm 15.0) \\
<0.01\end{array}$ \\
\hline $\begin{array}{l}\text { Number of people living in your house } \\
\text { (including yourself and the helper) } \\
1 \text { to } 4 \\
5 \text { Plus } \\
\text { p-value }\end{array}$ & $\begin{array}{c}76( \pm 22) \\
78( \pm 22) \\
0.08\end{array}$ & $\begin{array}{c}53( \pm 17) \\
50( \pm 17) \\
0.245\end{array}$ & $\begin{array}{c}66( \pm 23) \\
65( \pm 23) \\
0.468\end{array}$ & $\begin{array}{c}67.5( \pm 18.2) \\
67.5( \pm 17.5) \\
0.985\end{array}$ & $\begin{array}{c}73.7( \pm 14.6) \\
73.5( \pm 15.4) \\
0.747\end{array}$ \\
\hline $\begin{array}{l}\text { Have you been abiding by the social } \\
\text { distancing / stay at home? } \\
\text { No } \\
\text { Yes (all the time/often) } \\
\text { p-value }\end{array}$ & $\begin{array}{c}79( \pm 27) \\
77( \pm 22) \\
0.545\end{array}$ & $\begin{array}{c}43( \pm 15) \\
52( \pm 17) \\
0.292\end{array}$ & $\begin{array}{c}61( \pm 25) \\
65( \pm 23) \\
0.357\end{array}$ & $\begin{array}{c}65.3( \pm 20.8) \\
67.6( \pm 178) \\
0.524\end{array}$ & $\begin{array}{c}77.5( \pm 14.0) \\
73.5( \pm 15.0) \\
0.165\end{array}$ \\
\hline
\end{tabular}


have university degree. This study showed that there was an association between demographic information and the food hygiene knowledge and practices among residents of Lebanon, which conforms to the findings of previous studies. Our study revealed the high need for ongoing education efforts through different media means.

\section{References}

Byrd-Bredbenner C, Maurer J, Wheatley V, Schaffner D, Bruhn C, Blalock L, 2007. Food safety self-reported behaviors and cognitions of young adults: results of a national study. J Food Prot 70: 1917-26.

CDC, 2020. Coronavirus (COVID-19), available from https://www.cdc.gov/coronavirus/2019ncov/index.html. Accessed on 20.06.12

Hassan HF, Dimassi H, 2014. Food safety and handling knowledge and practices of Lebanese university students. Food Control 40: 127-33.

Hassan HF, Dimassi H, 2017. Usage and Understanding of Food Labels among Lebanese Supermarket Shoppers. Int J Consum Stud 41: 570-5.

Hassan HF, Dimassi H, 2018. Self-reported food safety knowledge and practices of Lebanese food handlers in Lebanese households. Br Food J 120: 518-30.

Health Canada, 2020. Coronavirus disease (COVID-19) and food safety, available from https://www.canada.ca/en/healthcanada/services/food-nutrition/foodsafety/covid19.html. Accessed on 20.06.12
Garayoa R, Córdoba M, García-Jalón I, Sanchez-Villegas A, Vitas AI, 2005. Relationship between consumer food safety knowledge and reported behavior among students from health sciences in one region of Spain. J Food Prot 68: 2631-6.

Gong S, Yang Y, Shen H, Wang X, Guo H, Bai L, 2011. Meat handling practices in households of Mainland China. Food Control 22: 749-55.

Gong S, Wang X, Yang Y, Bai L, 2016. Knowledge of food safety and handling in households: A survey of food handlers in Mainland China. Food Control 64: 45-53.

Lazou T, Georgiadis M, Pentieva K, Mckevitt A, Iossifidou E, 2012. Food safety knowledge and food handling practices of Greek university students: a questionnaire-based survey. Food Control 28: 400-11.

Migliorati G, Prencipe VA, Iannetti L, Giannatale ED, Matteucci O, Salini R, Calistri P, 2015. Survey of domestic food purchases and related home handling practices in the Abruzzo region (central Italy): data collection and analysis through a language-independent classification system. Food Control. Food Control 49: 23-33.

Osaili TM, Obeidat BA, Jamous DO, Bawadi HA, 2011. Food safety knowledge and practices among college female students in north of Jordan. Food Control 22: 269-76.

Ovca A, Jevsnik M, Raspor P, 2014. Food safety awareness, knowledge and practices among students in Slovenia. Food
Control 42: 144-51.

Sanlier N, 2009. The knowledge and practice of food safety by young and adult consumers. Food Control 20: 538-42.

Sharif L, Al-Malki T, 2010. Knowledge, attitude and practice of Taif University students on food poisoning. Food Control 21: 55-60.

Unusan N, 2007. Consumer food safety knowledge and practices in the home in Turkey. Food Control 18: 45-51.

US FDA, 2020. Shopping for Food During the COVID-19 Pandemic - Information for Consumers, available from https://www.fda.gov/food/food-safetyduring-emergencies/shopping-foodduring-covid-19-pandemic-information-consumers/. Accessed on 20.06.12

US EPA, 2020. List of Disinfectants for use against SARS-CoV-2 (COVID-19), available from https:/www.epa.gov/p esticide-registration/list-n-disinfectants-use- against-sars-cov-2-covid-19. Accessed on 20.06.12

Van Doremalen N, Bushmaker T, Morris DH, Holbrook MG, Gamble A, Williamson BN, Tamin A, Harcourt JL, Thornburg NJ, Gerber SI, Lloyd-Smith JO, de Wit E, Munster VJ, 2020. Aerosol and surface stability of SARSCoV-2 as compared with SARS-CoV-1. N Engl J Med 382: 1564-7.

WHO, 2020). Coronavirus, available from https://www.who.int/healthtopics/coronavirus\#tab=tab_1. Accessed on 20.06.12 